\title{
Effects of Rainfall Intensity and Vegetation Cover on Erosion Characteristics of a Soil Containing Rock Fragments Slope
}

\author{
Bingqin Zhao $\mathbb{D}^{1,2,3}$ Lun Zhang ${ }^{1}{ }^{1,2,3}$ Zhenyao Xia, ${ }^{1,2,3}$ Wennian Xu, ${ }^{1,2,3}$ Lu Xia, ${ }^{1,2,3}$ \\ Yongzhe Liang, ${ }^{4}$ and Dong Xia ${ }^{3,5}$ \\ ${ }^{1}$ College of Civil Engineering \& Architecture, China Three Gorges University, Yichang, Hubei 443002, China \\ ${ }^{2}$ Key Laboratory of Disaster Prevention and Mitigation, China Three Gorges University, Yichang, Hubei 443002, China \\ ${ }^{3}$ Collaboration Innovation Center for Geo-Hazards and Eco-Environment in Three Gorges Area, China Three Gorges University, \\ Yichang, Hubei 443002, China \\ ${ }^{4}$ China Power Construction Guiyang Engineering Corporation Limited, Guiyang, Guizhou 550081, China \\ ${ }^{5}$ Engineering Research Center of Eco-environment in Three Gorges Reservoir Region, Ministry of Education, \\ China Three Gorges University, Yichang, Hubei 443002, China
}

Correspondence should be addressed to Dong Xia; xiadongsanxia@163.com

Received 20 May 2019; Revised 14 August 2019; Accepted 28 August 2019; Published 17 September 2019

Academic Editor: Giulio Dondi

Copyright ( 2019 Bingqin Zhao et al. This is an open access article distributed under the Creative Commons Attribution License, which permits unrestricted use, distribution, and reproduction in any medium, provided the original work is properly cited.

Rainfall events coupled with shallow and gravelly sloping farmland have led to serious soil erosion and associated problems in the Three Gorges reservoir. Previous studies have shown that the use of vegetation is an effective way to control soil erosion. Therefore, an artificial, simulated rainfall experiment study is conducted to determine the effect of rainfall intensity and vegetation cover on runoff volume, sediment load, and runoff hydraulics characteristics. The experiment consists of seven vegetation treatments subjected to three rainfall intensities on a soil that contains rock fragments on a slope of $30^{\circ}$. The results indicate that the runoff volume and sediment load of the bare plot were greater than those of vegetation-covered plots under three different rainfall intensities. When Cynodon dactylon and Indigofera amblyantha were applied together, the plot displayed the best performance for soil loss control, with a reduction of $87.88 \%-99.11 \%$. According to a redundancy analysis, the change in rainfall intensity had the least impact on the Reynolds number and the runoff volume of the herb-shrub mixed plot in this study. These findings suggest that the effect of combining Cynodon dactylon and Indigofera amblyantha and increasing the vegetation coverage is an effective solution for soil and water loss conservation. The application of this method can alleviate environmental stress on the Three Gorges reservoir.

\section{Introduction}

Soil erosion is a major environmental problem worldwide, especially the water erosion caused by rainfall [1]. Approximately one sixth of the land area in the world has been affected by soil degradation in the historic past, and $55.6 \%$ of the affected area has been reported as being damaged by water erosion [2]. Thus, soil erosion control is a prevailing global problem that urgently needs to be solved $[3,4]$. The Three Gorges reservoir is located in the lower section of the upper reaches of the Yangtze river, and the total area of this region is approximately $58000 \mathrm{~km}^{2}$. The area of soil erosion in the Three Gorges reservoir constitutes $51 \%$ of the total region, and the annual average amount of soil erosion is nearly 200 million tons, which is one of the four most serious soil and water erosion regions of the upper Yangtze river $[5,6]$. Severe soil erosion has led to a series of environmental problems, such as high rates of alluvial sedimentation, rises in streambed elevation, frequent geohazards, and environmental deterioration. These effects have imperiled the efficient operation of the Three Gorges Dam [6]. Since the construction of the Three Gorges Dam, the study of soil erosion controlling factors, soil erosion processes, runoff and sediment yield characteristics, and the prediction and 
prevention of soil erosion in the Three Gorges reservoir have attracted the attention of many researchers [7-10].

The area of farmland in the Three Gorges reservoir is very limited $\left(12560 \mathrm{~km}^{2}\right)$, and sloped farmland occupies $74 \%$ of the total farmland area in the region [6]. However, soil erosion of farmland has accounted for $60 \%$ of the total soil erosion in the Three Gorges reservoir region. The sediment yield of the farmland accounts for $46 \%$ of the total sediment yield in the Three Gorges reservoir region $[6,11,12]$. Therefore, sloped farmland is the predominant source of soil and water erosion in the reservoir. The characteristics for the sloped farmland in the reservoir of shallow and gravelly are very distinct. The content of gravel in the soil in the sloped farmland of the reservoir is approximately 5\%-30\% [13]. Rainfall is the main driver of soil loss in sloped farmlands, while the Three Gorges reservoir has an abundance of precipitation and rainstorms. Serious soil erosion causes heavy losses in surface material and soil nutrients, decreases in farmland productivity, degradation of farmland, and even soil desertification and lithodesertification [6, 7]. Engineering measures, botanical measures, and farming measures have been integrated to control soil erosion and reduce sediment yield in the reservoir [6,9]. Artificial restoration measures have also been used to prohibit the land from farming [9]. Thus, research that investigates erosion characteristics on sloped farmland is of very practical significance.

Rainfall is a prerequisite for runoff and soil water erosion, and the soil erosion amount and runoff amount are determined not only by rainfall intensity and rainfall quantity but also by land use patterns [8]. Vegetation is a sensitivity factor that affects soil erosion, and the use of vegetation mitigation measures is an effective way to control soil erosion caused by water $[14,15]$. The ability of vegetation to intercept rainfall, weaken splash effects, and control surface runoff is the result of the combined effects of leaves, stems, roots, and litter, thus performing the function of soil and water conservation [14-16]. The role of the interception of rainfall by plant leaves and stems reduces the effective precipitation on a slope and the erosion effect on a slope's surface. In addition, the buffer function of plant leaves and stems can effectively weaken the kinetic energy of raindrops and disperse a big raindrop into a small raindrop, leading to less energy that is splashed on the soil $[14,17]$. Vegetation root development can improve the physical properties of soil, such as soil strength, structural stability, and aggregate stability, which are closely related to soil erodibility. In addition, the roots can increase the soil infiltration capacity, thus resulting in a contribution to soil and water conservation $[15,18,19]$. Moreover, the effect of vegetation on soil erosion is substantial due to the ability to change hydraulic parameters and the runoff and sediment yield conditions [20]. Some studies have indicated that the flow velocity, flow depth, Reynolds numbers, and Froude numbers decrease with increasing grassland coverage, while the resistance coefficients increase [21, 22]. Other studies have demonstrated that the flow velocity and Reynolds numbers increase with increasing slope gradient, while the flow depth and resistance coefficients decrease [23, 24]. Additionally, Yang et al., who studied rigid vegetation, found that the resistance coefficients increased with increasing Reynolds numbers [25]. Studies on the different vegetation types have indicated that there is a significant relationship between resistant coefficients and flow depth [26, 27].

Accordingly, the existence of vegetation makes the study of runoff and sediment characteristics more complex. Therefore, the runoff and sediment yielding characteristics under different vegetation covers and rainfall conditions require further study. Previous studies have primarily considered the laws of runoff and sediment under different soil types, different land use types, different slope gradients, and different rainfall intensities [9, 10, 15, 27]. However, for the soil containing rock fragments slope, studies regarding the soil erosion characteristics under different rainfall intensities have been fewer. In addition, fewer soil erosion characteristics have been studied under different vegetation restoration models on the soil containing rock fragments slope in the reservoir. In particular, studies regarding runoff and sediment yield effects, hydraulic characteristics, and the relationship between them are conducive to quantitative research on the mechanism of slope soil erosion under various vegetation covers. Therefore, in this study, soil containing rock fragments slope is used as the subject of study, and research on the effect of seven levels of vegetation coverage and three levels of rainfall intensities on the erosion characteristics of soil slopes that contain rock fragments are examined. The objective of this study is to evaluate the impact on soil and water loss resulting from different rainfall intensities and vegetation treatments and apply this information to improve vegetation restoration models that aim to protect water and soil loss. In addition, this study will provide useful information for soil conservation at the Three Gorges reservoir and increase researchers' understanding of this region that is experiencing serious soil erosion.

\section{Materials and Methods}

2.1. Experimental Design. This study was conducted at the Water and Soil Conservation Experiment Base at the China Three Gorges University in Yichang City $\left(111^{\circ} 18^{\prime} \mathrm{E}\right.$ and $30^{\circ} 43^{\prime} \mathrm{N}$ ), which is located in the southwest of the Hubei Province. The rainfall simulation experiments were conducted on a $30^{\circ}$ slope under $60 \mathrm{~mm} / \mathrm{h}, 90 \mathrm{~mm} / \mathrm{h}$, and $120 \mathrm{~mm} / \mathrm{h}$ rainfall intensities, which are representative of the typical sloped farmland gradient and rainfall intensities in the Three Gorges reservoir area [28]. The plants selected in this research were Cynodon dactylon and Indigofera amblyantha, which were two common plants in Three Gorges reservoir with well-developed root systems and adaptation to poor soils [29]. Table 1 shows the investigated levels of the vegetation coverage. The vegetation coverage was measured using vertical photographs of the surface for each plot with a digital camera, and then, ERDAS Imagine2011 analysis software was used to test vegetation coverage. The vegetation coverage was adjusted as needed to reach design requirements. The coverage of Cynodon dactylon was controlled by pulling the weeds. The Indigofera amblyantha coverage was controlled by seedling raising and 
TABLE 1: Vegetation patterns in the different runoff plots.

\begin{tabular}{|c|c|c|c|c|c|c|c|c|}
\hline & $\mathrm{CK}$ & S1 & S2 & S3 & S4 & S5 & S6 & S7 \\
\hline $\begin{array}{l}\text { Vegetation } \\
\text { type }\end{array}$ & Unplanted & & Cynodon dactylon & & \multicolumn{2}{|c|}{$\begin{array}{c}\text { Indigofera } \\
\text { amblyantha }\end{array}$} & \multicolumn{2}{|c|}{$\begin{array}{c}\text { Cynodon dactylon }+ \\
\text { Indigofera } \\
\text { amblyantha }\end{array}$} \\
\hline $\begin{array}{l}\text { Vegetation } \\
\text { coverage }\end{array}$ & $0 \%$ & $60 \%$ & $80 \%$ & $100 \%$ & $60 \%$ & $80 \%$ & $60 \%$ & $100 \%$ \\
\hline
\end{tabular}

transplanting. A total of 24 treatment combinations were conducted. Each simulated rainfall of a treatment lasted 30 minutes. The $\mathrm{CK}$ plot was not covered with vegetation and served as a control.

The experimental soil was collected from the surface red soil of the slope farmland from a hilly area in Yichang City, Hubei Province. The particle size of the experimental red soil consisted of $8.6 \%$ sand, $74.6 \%$ silt, and $16.8 \%$ clay. The content of organic matter, total nitrogen, total phosphate, available nitrogen, and available phosphate was $0.60 \mathrm{~g} / \mathrm{kg}, 0.65 \mathrm{~g} / \mathrm{kg}$, $0.89 \mathrm{~g} / \mathrm{kg}, 45.24 \mathrm{mg} / \mathrm{kg}$, and $5.52 \mathrm{mg} / \mathrm{kg}$, respectively. The term "stone" can be used as a general term for all coarse fragments having diameters larger than $2 \mathrm{~mm}$ [30]. The mass percent of stones in the soil was used to characterize the experimental plots and express the quantity of stone in soil in this research. The stone used in this research was taken from the Nanjinguan sand factory in Yichang City and separated on a $2 \mathrm{~mm}$ sieve. The design content of stone in this research was determined to be $10 \%$ (the percentage of stone by mass of the soil) and was based on the local gravel distribution. The red soil was dried naturally and then thoroughly mixed with stone to minimize the differences among treatments. The $40 \mathrm{~cm}$ thick soil was packed in each soil bin in $10 \mathrm{~cm}$ increments with the sieved soil at a bulk density of $1.25 \mathrm{~g} / \mathrm{cm}^{3}$. The weight of the red soil and stone in each layer were determined by the soil bin volume, the soil bulk density, and the content of stone.

The experimental equipment used in this research primarily consisted of soil bins and a rainfall simulator. The dimension of the experimental soil bin was $2 \mathrm{~m} \times 0.5 \mathrm{~m} \times 0.45 \mathrm{~m}$ (length $\times$ width $\times$ height). Two intakes were placed at different heights from the bottom of the slope and used to collect surface runoff and subsurface runoff (see Figure 1). A total of 8 experimental soil bins were made and the vegetation patterns were controlled according to Table 1 . The rainfall simulator used in the experiment was manufactured by Nanlin Electronics Technology Limited in Nanjing, China. The rainfall simulator consisted of an array of nine groups of nozzles that were installed at a height of $4 \mathrm{~m}$. The expected rainfall intensity was adjusted by pressure and nozzle spacing, and the uniformity of the rainfall intensities was greater than 0.86 . Calibration tests were conducted before proceeding with the rainfall experiments. To guarantee the experimental accuracy, the rainfall experiments were conducted under windless conditions. Prior to the rainfall experiments, a rainfall intensity of $30 \mathrm{~mm} / \mathrm{h}$ was applied until rainfall runoff began. A plastic sheet was used to cover the plot for 24 hours to allow the water to completely permeate through the soil, maintain the moisture of the test soil at close to a natural soil condition, and ensure that the soil moisture remained the same for each rainfall event.

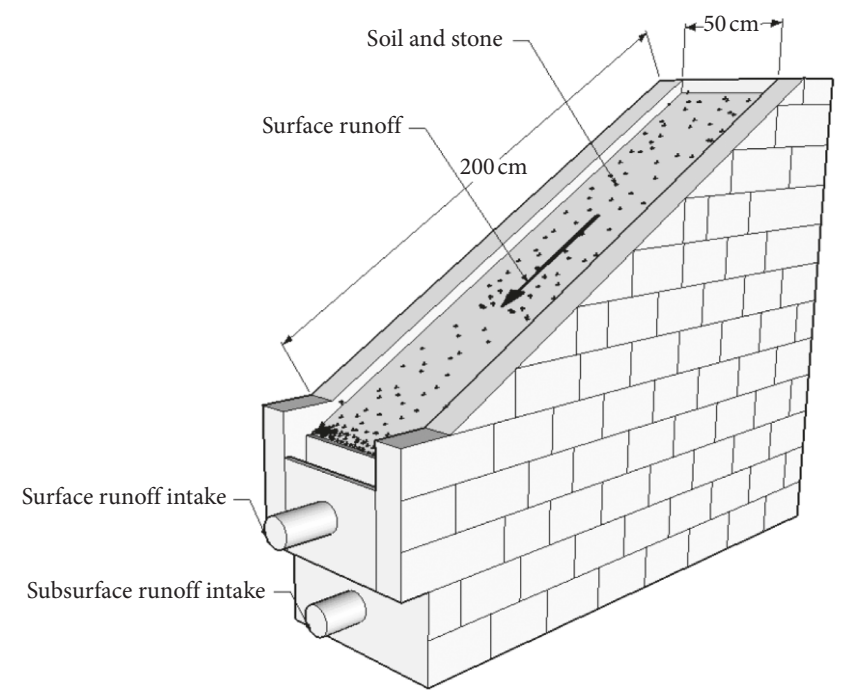

FIGURE 1: Schematic diagram of the experimental soil bin used in the simulated rainfall experiments.

2.2. Sampling and Analytical Method. The runoff volume and sediment load datum were collected in a plastic container at 3 minutes intervals during the 30 minutes duration of rainfall time. The dye trace method was used to measure the surface flow velocity $(V s)$. The time elapsed for the dye tracer to travel across the flume was determined using a stopwatch according to the color-front propagation. And then, it was converted into the profile mean velocity $(V)$ via the relation of $V=\alpha V s$, which assumes a vertical velocity distribution with respect to the water depth in laminar flow, followed by a quadratic equation with the value of the coefficient $\alpha$ equal to $0.67[31,32]$. Once the rainfall experiment was completed, the rainfall and sediment samples were settled for 24 hours in a plastic container until the sediment was completely deposited on the bottom of the plastic container. Then, the supernatant water was poured out from the sample, and thus, the sediment was collected. The sediments were dried in an oven to a constant weight at $105^{\circ} \mathrm{C}$ for $6-8$ hours and then weighed to determine the dry sediment weight. The runoff and erosion rates were determined by dividing the runoff volume and the sediment load per unit area by the period of time, respectively.

2.3. Data Analysis and Statistical Method. The parameter of surface runoff hydraulic characteristic generally includes the Reynolds number, the Froude number, the Darcy-Weisbach friction coefficient, and Manning's roughness coefficient [33-36]. The Reynolds number is the ratio of the inertial 
force and viscous force, which is a nondimensional parameter to reflect the turbulent intensity of surface runoff. The value of the Reynolds number is the quantitative criteria for determining laminar flow and turbulent flow with a critical value of 500 [35]. The specific calculation formula of the Reynolds number is as follows:

$$
\operatorname{Re}=\frac{V h}{v},
$$

where Re is the Reynolds number; $V$ is the profile mean velocity $(\mathrm{m} / \mathrm{s}) ; h$ is the flow depth $(\mathrm{m})$; and $v$ is the kinematical viscosity $\left(\mathrm{m}^{2} / \mathrm{s}\right)$.

The Froude number is the ratio of the inertial force and the gravity force, which is a nondimensional parameter to indicate the occurrence of tranquil flow and supercritical flow with a critical value of 1 [35]. The specific calculation formula of the Froude number is as follows:

$$
\operatorname{Fr}=\frac{V}{\sqrt{g h}}
$$

where Fr is the Froude number and $g$ is the acceleration of gravity $\left(\mathrm{m} / \mathrm{s}^{2}\right)$.

The Darcy-Weisbach friction coefficient and Manning's roughness coefficient are the common hydraulic parameters used to reflect the characteristic of water resistance. They are calculated according to calculation formulas as follows:

$$
\begin{aligned}
& f=\frac{8 g h J}{V^{2}}, \\
& n=\frac{h^{2 / 3} J^{1 / 2}}{V},
\end{aligned}
$$

where $f$ is the Darcy-Weisbach friction coefficient, $n$ is Manning's roughness coefficient, and $J$ is the hydraulic slope, and it is the sine function of slope gradient $(\mathrm{m} / \mathrm{m})$.

The relationships between vegetation coverage, rainfall intensity, and runoff characteristics are determined using the redundancy method (DCA). The vegetation coverage and rainfall intensity are used as environmental variables, and the runoff characteristics are used as "species" variables. In this way, the relationship between these variables can be directly compared [37]. The significance relationship between environmental variables and runoff characteristics is assessed using a Monte Carlo permutation test with 499 permutations [32]. The RDA is conducted using CANOCO 4.5 software (Centre for Biometry, Wageningen, Netherlands) [38].

\section{Results}

3.1. Runoff Volume and Sediment Load. The dynamic variation trends of runoff volume and sediment load under different rainfall intensities and vegetation cover are shown in Figure 2. Under the same rainfall intensity, the runoff volume of the CK plot was consistently much greater than those in the vegetation-covered plots during the entire rainfall process. Under the same rainfall intensity and vegetation type, the runoff volume decreased with increasing vegetation coverage. The variation in the runoff volume with increasing duration of rainfall showed an unsteady increase in runoff volume followed by a steady condition. Then, the runoff volume remained nearly constant with small variations until the end of each rainfall event, though the steady points of each plot were different and occurred at different times. The process of sediment loading exhibited greater fluctuations compared with runoff volume, especially in the CK plot. The sediment loads mostly increased with prolonged rainfall duration as a whole, and the sediment loads exhibited different degrees of dependence on vegetation coverage and rainfall intensity. It can be seen from Figure 2 that the amount of sediment load in the CK plot was significantly higher than the sediment load in the other plots under the same rainfall intensity.

The differences in runoff and sediment rates were obvious, both between the $\mathrm{CK}$ plot and vegetation-covered plots under the same rainfall intensity and within different rainfall intensities in the same plot (see Table 2). Higher runoff and sediment rates were observed on the CK plot than those on the vegetation-covered plots. The minimum runoff rate and sediment rate typically occurred in plot S7. Both the runoff rate and sediment rate decreased with increasing vegetation coverage for the same vegetation type under the three different rainfall intensities. In conclusion, vegetation type had an appreciable influence on the runoff rate and sediment rate for each plot under the three rainfall intensities. The accumulated runoff volume and accumulated sediment load that occurred on the CK plot were always higher than those on the vegetation-covered plots under the three rainfall intensities (see Table 2). The accumulated runoff volume and the accumulated sediment load of the shrub plots were typically higher than those in herb plots with the same vegetation coverage under rainfall intensities of $60 \mathrm{~mm} / \mathrm{h}$ and $90 \mathrm{~mm} / \mathrm{h}$. Under a heavy rainfall intensity $(120 \mathrm{~mm} / \mathrm{h})$, the accumulated runoff volume and the accumulated sediment load of the herb plots were higher than the shrub plots.

3.2. Runoff Hydraulic Characteristics. The runoff hydraulic characteristics, including the Reynolds number $(\mathrm{Re})$, the Froude number (Fr), the Darcy-Weisbach friction coefficient $(f)$, and Manning's roughness coefficient $(n)$, under different vegetation covers and different rainfall intensities are shown in Figure 3. The flow form of all the plots was laminar flow with the Reynolds numbers smaller than 500 [35]. The Reynolds numbers of the bare plots were greater than the vegetation-covered plots under the three different rainfall intensities. Under the same rainfall intensity and vegetation type, the Reynolds number decreased with increasing vegetation coverage. The Reynolds number increased with increasing rainfall intensity for the same plot. In addition, aside from the $\mathrm{CK}$ plots under three different rainfall intensities and the S1 and S4 plots under the rainfall intensity of $120 \mathrm{~mm} / \mathrm{h}$, the Froude numbers of most of the other plots were less than 1 . These results indicate that the surface runoff form on the CK plot under three different rainfall intensities and the S1 and S4 plots under the rainfall intensity of $120 \mathrm{~mm} / \mathrm{h}$ were supercritical and the surface runoff on the other plots was tranquil [35]. The Froude numbers of the bare 


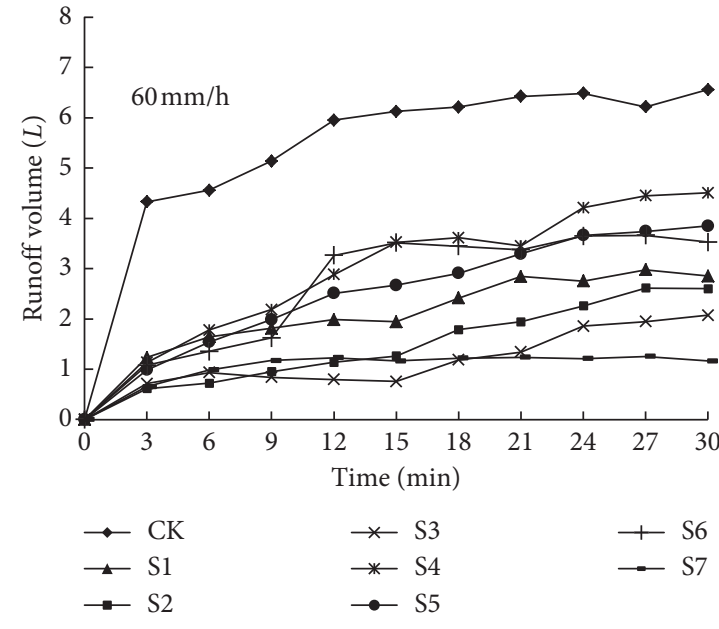

(a)

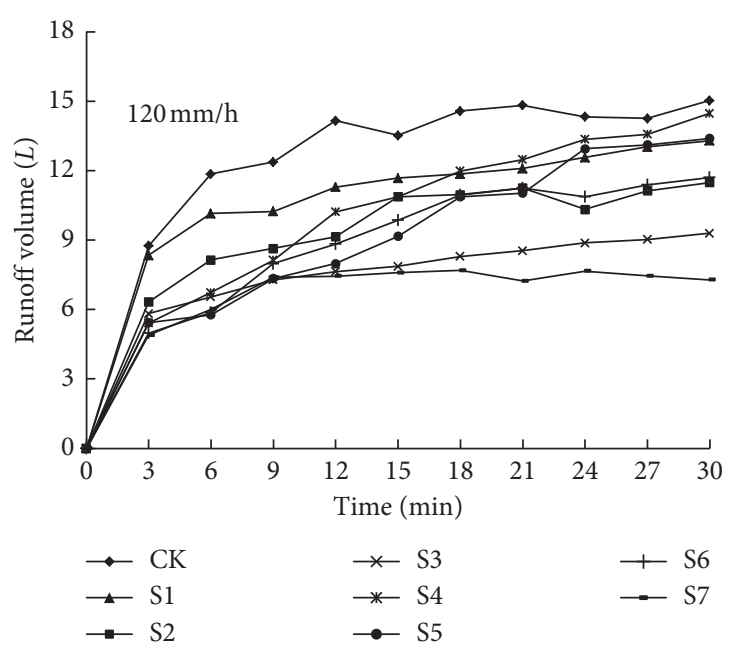

(c)

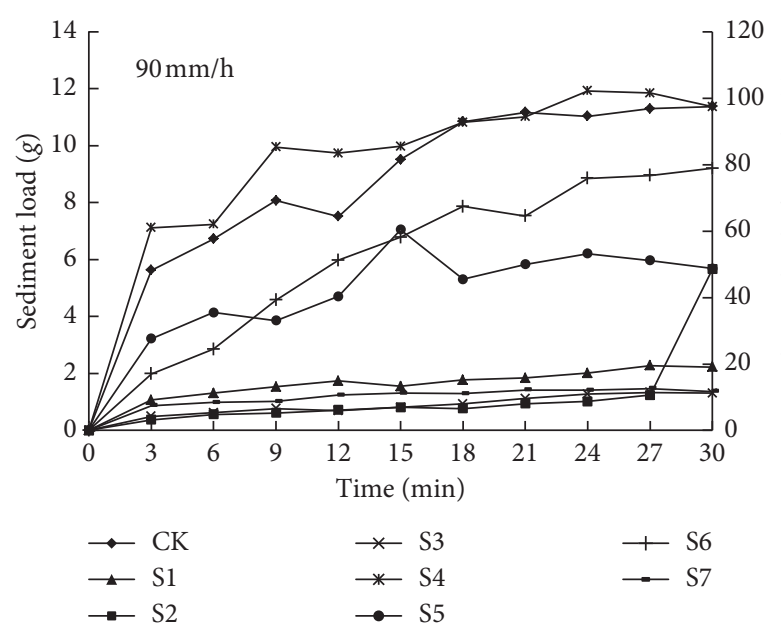

(e)

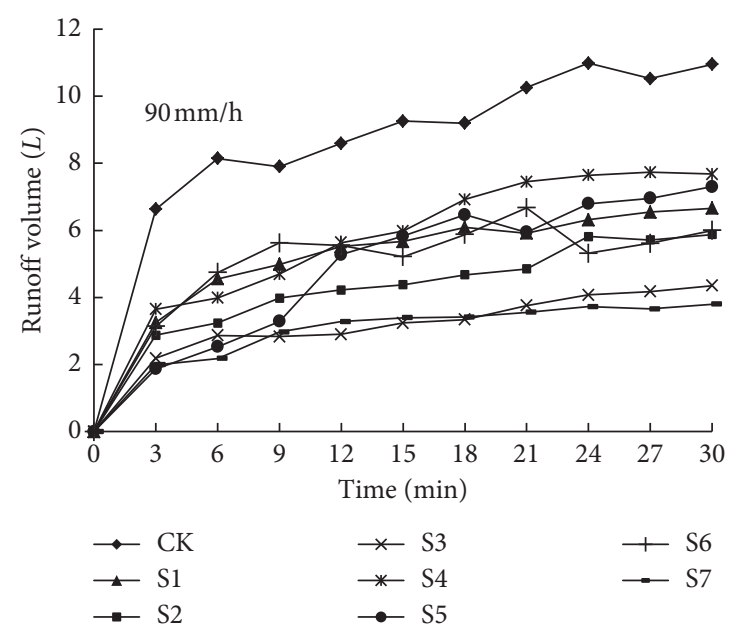

(b)

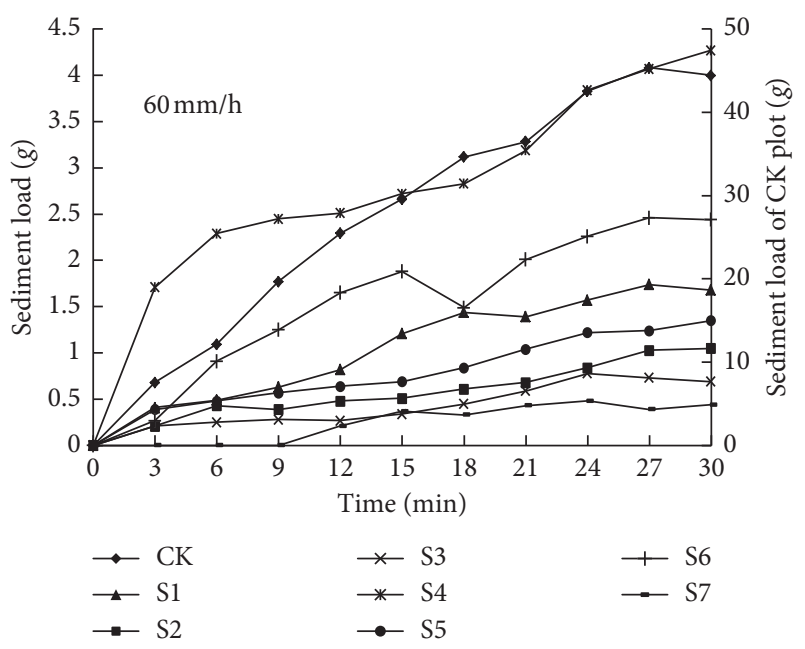

(d)

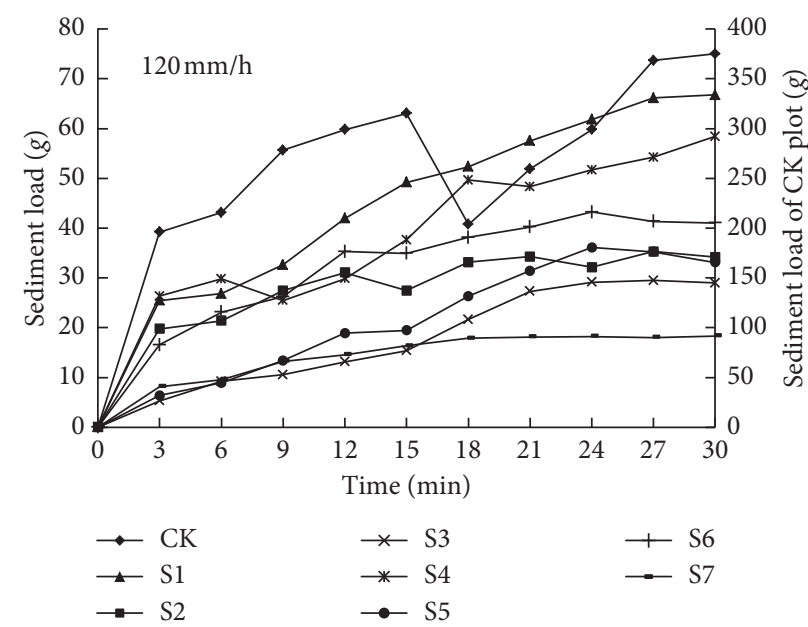

(f)

Figure 2: Changes in runoff volume and sediment loads under different rainfall intensities and vegetation coverages.

plots were greater than the vegetation-covered plots under the three different rainfall intensities. Under the same rainfall intensity and vegetation type, the Froude number decreased with increasing vegetation coverage. Both the Darcy-
Weisbach friction coefficient and Manning's roughness coefficient increased with increasing vegetation coverage under the three different rainfall intensities. The lowest DarcyWeisbach friction coefficient and Manning's roughness 
TABLE 2: Accumulated runoff volumes and sediment loads under different vegetation covers and rainfall intensities.

\begin{tabular}{|c|c|c|c|c|c|c|c|c|}
\hline \multirow{2}{*}{$\begin{array}{l}\text { Rainfall intensity } \\
(\mathrm{mm} / \mathrm{h})\end{array}$} & \multicolumn{8}{|c|}{ Plots } \\
\hline & $\mathrm{CK}$ & S1 & S2 & S3 & S4 & S5 & S6 & S7 \\
\hline \multicolumn{9}{|l|}{ Runoff rate $(\mathrm{cm} / \mathrm{s})$} \\
\hline 60 & 21.3 & 3.9 & 3.3 & 2.6 & 5.5 & 4.5 & 5.1 & 2.4 \\
\hline 90 & 29.1 & 7.2 & 6.1 & 4.9 & 8.2 & 6.1 & 7.5 & 4.7 \\
\hline 120 & 42.9 & 12 & 9.9 & 7.2 & 10.9 & 8.3 & 8.7 & 6.2 \\
\hline \multicolumn{9}{|l|}{ Runoff volume (L) } \\
\hline 60 & 58.02 & 22.48 & 15.9 & 12.45 & 31.75 & 27.16 & 28.5 & 11.31 \\
\hline 90 & 92.44 & 55.5 & 45.63 & 33.72 & 61.36 & 52.24 & 53.75 & 31.94 \\
\hline 120 & 133.66 & 114.52 & 98.28 & 79.19 & 107.25 & 97.05 & 93.68 & 70.61 \\
\hline \multicolumn{9}{|c|}{ Sediment rate $(\mathrm{g} / \mathrm{min})$} \\
\hline 60 & 9.93 & 0.38 & 0.21 & 0.15 & 1.00 & 0.28 & 0.55 & 0.09 \\
\hline 90 & 26.62 & 0.58 & 0.42 & 0.31 & 3.37 & 1.73 & 2.15 & 0.41 \\
\hline 120 & 93.65 & 16.02 & 9.87 & 6.34 & 13.71 & 7.64 & 11.34 & 5.09 \\
\hline \multicolumn{9}{|l|}{ Sediment load $(g)$} \\
\hline 60 & 297.86 & 11.38 & 6.23 & 4.59 & 29.88 & 8.46 & 16.62 & 2.65 \\
\hline 90 & 798.55 & 17.33 & 12.7 & 9.34 & 101.02 & 51.99 & 64.6 & 12.38 \\
\hline 120 & 2809.42 & 480.69 & 296.11 & 190.2 & 411.3 & 229.25 & 340.22 & 152.55 \\
\hline
\end{tabular}
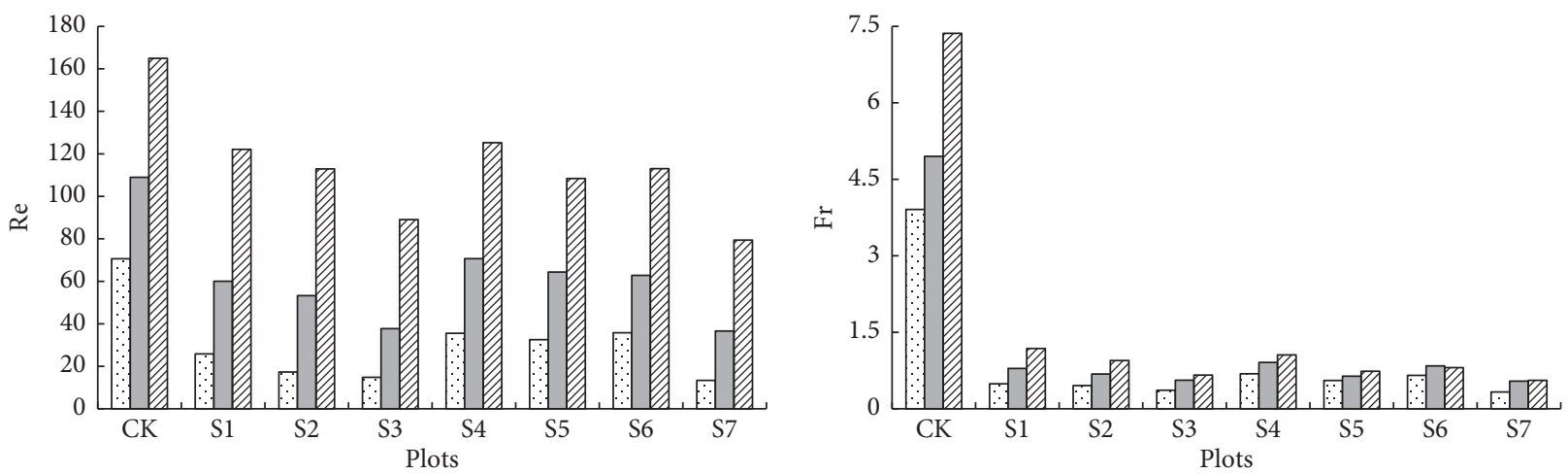

: $60 \mathrm{~mm} / \mathrm{h}$

[. $60 \mathrm{~mm} / \mathrm{h}$

$\square 90 \mathrm{~mm} / \mathrm{h}$

$\square 90 \mathrm{~mm} / \mathrm{h}$

\ $120 \mathrm{~mm} / \mathrm{h}$

Z $120 \mathrm{~mm} / \mathrm{h}$

(a)

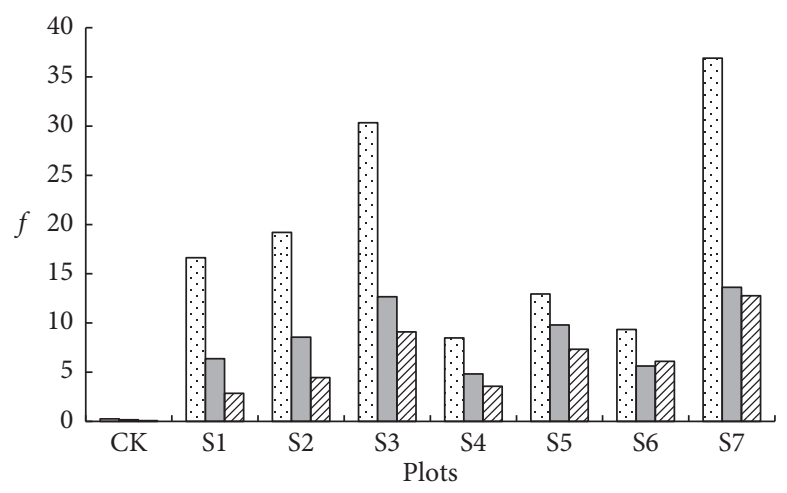

(b)

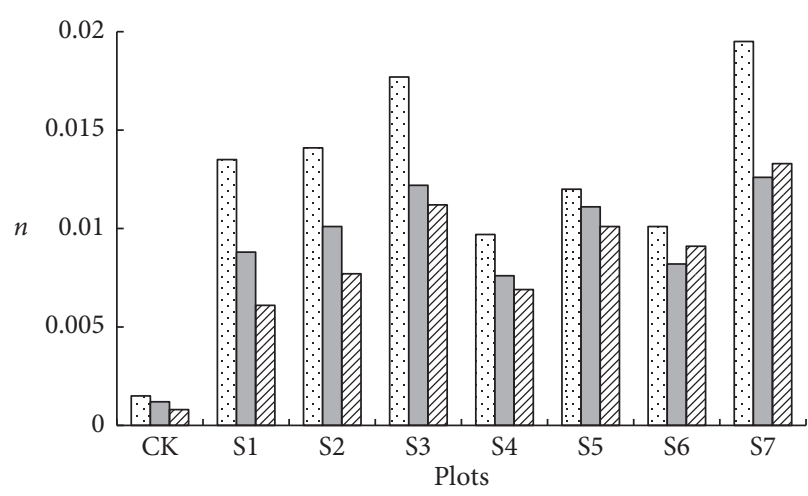

$60 \mathrm{~mm} / \mathrm{h}$
$90 \mathrm{~mm} / \mathrm{h}$
$120 \mathrm{~mm} / \mathrm{h}$

$60 \mathrm{~mm} / \mathrm{h}$
$90 \mathrm{~mm} / \mathrm{h}$
$\square 120 \mathrm{~mm} / \mathrm{h}$

(c)

(d)

FIgURE 3: Runoff hydraulic characteristics under different vegetation covers and rainfall intensities. 
coefficient occurred in the S4 plot under the rainfall intensities of $60 \mathrm{~mm} / \mathrm{h}$ and $90 \mathrm{~mm} / \mathrm{h}$ and in the $\mathrm{S} 1$ plot under the rainfall intensity of $120 \mathrm{~mm} / \mathrm{h}$. And the highest DarcyWeisbach friction coefficient and Manning's roughness coefficient occurred in the S7 plot under the three different rainfall intensities.

\section{Discussion}

4.1. Effect of Vegetation Cover and Rainfall Intensity on Runoff and Sediment. Rainfall runoff is an indicator used to measure soil erosion of a slope. Runoff occurs when the rainfall intensity is greater than the infiltration intensity, and this causes excess water to fail to infiltrate [39]. The variation in steady point timing and stable runoff volume in each plot can be ascribed to different ground coverages [14, 39]. For the vegetation-covered plots, the steady point reflected that the rainfall interception ability of the plant stems and leaves had reached a saturation point after a period of runoff initiation, and this induced the precipitation at the slope surface soil to achieve steady infiltration. For the three different rainfall intensities, the herb showed a better water interception capacity as compared to the shrub (see Figure 2). This is because the plant height of the herb was lower than the shrub and formed a more intensive interception layer on the slope surface, thus relatively well preventing the raindrop splash slope surface directly. In addition, the interception of rainfall by the shrub created an inner precipitation and increased the rainfall duration. Additionally, a vegetation root can enhance soil permeability by means of being embedded in, entangled in, and enwrapped in soil. In this study, the permeability of the Cynodon dactylon plot was much greater than that in the Indigofera amblyantha plot that had a more fibrous root. The herb-shrub mixed plots showed better performance in interception capacity with lower runoff volume. According to Laio (see Figure 4), different vegetation types have various mechanisms in the soil water balance. The shrub can intercept rainfall directly, and the herb can intercept the inner precipitation produced by the shrub [40]. As a joint result of the shrub and the herb, the rainfall duration and infiltration time are extended, which can increase soil infiltration and lead a decrease in runoff volume.

In this study, vegetation cover dramatically reduced sediment loads in all the rainfall treatments, which was consistent with the results of Somchai and Chaiyuth and Lin (see Figure 2) [41, 42]. The generation of sediment erosion is a complex process and is comprehensively influenced by rainfall intensity, soil property, slope gradient, vegetation type, and other factors $[9,12,15,30,32,39,41]$. Vegetation type has also been demonstrated to be an important factor that impacts runoff and sediment yields on a slope $[16,42,43]$. A covering of vegetation on the soil surface increases the soil surface roughness and acts as successive barriers that impede surface runoff and increase the infiltration time $[9,42]$. Thus, land cover reduces the sediment load by effectively intercepting rainfall runoff, increasing the surface roughness of the soil, and promoting rainfall infiltration. Yu et al. also mentioned that when the vegetation

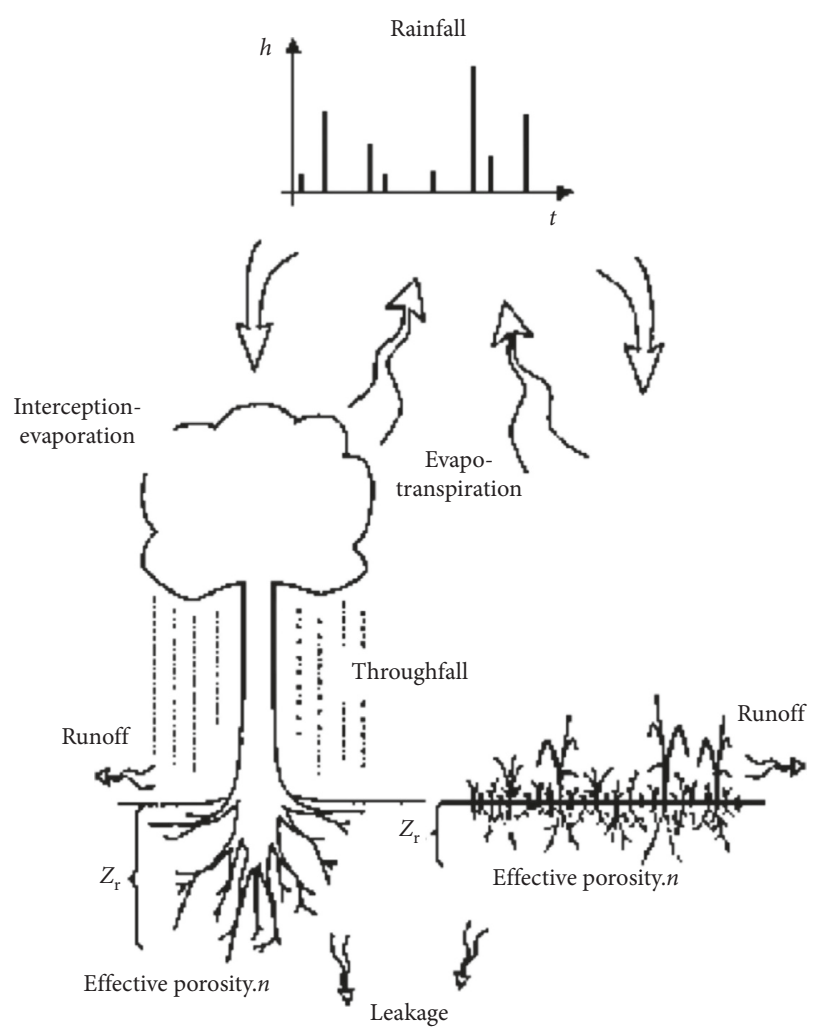

FIGURE 4: Schematic representation of the various mechanisms of two different vegetation types that play a role in the soil water balance [40].

coverage on the land surface was relatively high, a raindrop cannot directly strike the ground surface due to the interception effect of the vegetation, which makes the kinetic energy of a raindrop weaken [44].

Rainfall sediment is a phenomenon of detachment and transportation of loose soil particles due to the effect of rain splash and surface runoff scouring that can transport particles away from their original position $[31,45]$. Previous studies have found that sediment load primarily depends on the capacity of splash erosion, detachment, and transportation of soil particles by raindrop kinetic energy [45]. The topsoil of a slope surface has a loose structure with a weak capacity of resistance to erosion. Hence, the topsoil structure is easily destroyed by raindrop splash erosion and surface erosion. The fine grains are transported selectively by runoff at the preliminary rainfall stage. As the runoff continues, the fine grain can be transported will gradually reduce. The sediment content on surface runoff decreases under the combined influence of the gradually crusted topsoil and the stability infiltration rate. At a later stage in the rainfall process, the soil macroaggregates are stripped away and dispersed from the soil by the raindrop, and a significant quantity of sediment particles are transported in surface runoff and causes a wavy fluctuation in the sediment load curve $[46,47]$.

A comparison of the accumulated runoff volume and sediment load shows that the cultivation of plants can effectively prevent and slow the formation of surface runoff and reduce the loss of slope surface soil. The runoff and 
sediment interception ability of herbs is better than shrubs in a light rainfall condition $(60 \mathrm{~mm} / \mathrm{h}$ and $90 \mathrm{~mm} / \mathrm{h})$, and the reverse result occurs with a higher rainfall intensity $(120 \mathrm{~mm} / \mathrm{h})$. With an increase in vegetation coverage, factors associated with slope coverage can decrease erosion by enhancing the protective effect of the surface slope and limiting soil detachment. Some studies have shown that the amount of sediment was controlled by transport limitation under the influence of low rainfall intensities, while it was controlled by detachment limitation under the influence of high rainfall intensities [48]. This result suggests that under a rainfall intensity of $60 \mathrm{~mm} / \mathrm{h}$ and $90 \mathrm{~mm} / \mathrm{h}$, the flow transport capacity was greater than the sediment detachment capacity. Hence, the erosion process was dominated by a sediment transport-limiting regime. When the rainfall intensity increased to $120 \mathrm{~mm} / \mathrm{h}$, the sediment detachment capacity was greater than the flow transport capacity. Hence, the erosion process was converted from a sediment transport-limiting regime to a detachment-limiting regime. Herbs formed a more intensive interception layer on the slope surface due to their lower plant height in this study; thus, they had a better reduction in erodibility and transportability under low rainfall intensities. However, the detachment capacity undergone by detaching soil particles from the soil surface is always controlled by the acting force of raindrop. A shrub can significantly weaken raindrop energy with flourishing stems and leaves; therefore, it has a lower runoff and sediment load under high rainfall intensity. In the case of the same rainfall intensity and vegetation type, the accumulated runoff volume and the accumulated sediment load decreased with increasing vegetation coverage. The residence time of raindrop that reached the slope surface was prolonged with an increase in vegetation coverage. Thus, the soil infiltration time was also shortened, making the runoff rate and runoff volume increase. In addition, an increase in runoff may strengthen the splash intensity and thus result in increased loose soil particles on the slope surface. With an increase in the runoff splashing power, these loose soil particles will be taken away more easily and thus form a greater amount of sediment.

4.2. Reduction Effects of Runoff and Sediment. The results of runoff volumes and sediment loads under different vegetation covers and rainfall intensities indicated that vegetation is an effective and acceptable measure for controlling runoff volume, thus relieving the scouring effect of rainfall on slope surfaces. To investigate the effect of the quality of vegetation type on the runoff volume and sediment load, the percentages of reduction in the accumulated runoff volume and the accumulated sediment load among different vegetation coverage plots were calculated. The runoff reduction $=($ the runoff volume of bare plot - the runoff volume of vegetation-covered plot)/the runoff volume of bare plot $\times 100 \%$ [41]. The sediment reduction $=($ the sediment load of bare plot - the sediment load of vegetation-covered plot)/the sediment load of bare plot $\times 100 \%$ [41]. These two indicators can characterize the benefits of plants on water and soil conservation [41, 49]. As shown in Figure 5, vegetation cover can significantly increase water and soil conservation benefits and, generally, the water and soil conservation benefits are better with higher vegetation coverage. The difference in runoff volume between bare plot and vegetation plots varied from $45.27 \%$ for plot S4 to $80.51 \%$ for plot S7 under a rainfall intensity of $60 \mathrm{~mm} / \mathrm{h}$, $33.62 \%$ for plot S4 to $65.45 \%$ for plot S7 under a rainfall intensity of $90 \mathrm{~mm} / \mathrm{h}$, and $14.32 \%$ for plot $\mathrm{S} 1$ to $47.17 \%$ for plot S7 under a rainfall intensity of $120 \mathrm{~mm} / \mathrm{h}$. The percentage reduction in sediment load for vegetation-covered plots relative to that of the bare plots ranged from $89.97 \%$ for plot S4 to $99.11 \%$ for plot S7 under a rainfall intensity of $60 \mathrm{~mm} / \mathrm{h}, 87.35 \%$ for plot S4 to $98.83 \%$ for plot S3 under a rainfall intensity of $90 \mathrm{~mm} / \mathrm{h}$, and $82.89 \%$ for plot $\mathrm{S} 1$ to $94.57 \%$ for plot S7 under a rainfall intensity of $120 \mathrm{~mm} / \mathrm{h}$. The decreasing degrees of the accumulated runoff volume and the accumulated sediment load were different for different vegetation types. But both plots S7 and S3 consistently had a better runoff and sediment reduction effect under the three different rainfall intensities. A comparison of the runoff and sediment reduction effects in this research showed that vegetation cover was far more effective at reducing sediment.

\subsection{Effect of Vegetation Cover and Rainfall Intensity on Runoff} Hydraulic Characteristics. The Reynolds number is a comprehensive reflection of the flow velocity and flow depth. In general, a higher Reynolds number indicates higher flow transport capacity and hydraulic erosion capacity $[21,50]$. It can be concluded that vegetation can improve the antierosion ability of a plot (see Figure 3 ). The presence of vegetation may lead to the flow around a circular cylinder phenomenon, which results in making it difficult for the surface runoff to spread along an entire slope's surface. The flow through vegetation is based on the minimum stream power concept [21]. Therefore, the inertial force of the surface runoff is decreased by the vegetation, and the viscous force caused by the water flow around the vegetation increases with increasing vegetation coverage. The Froude number reflects the relative proportions of the kinetic and potential energy of the surface runoff [34]. In this research, the potential energy of the surface runoff remained unchanged under the same slope angle condition. In addition, a portion of the kinetic energy of the surface runoff was consumed due to the drag effect of vegetation under the condition of vegetation coverage. The greater the vegetation coverage, the more the kinetic energy consumed, and a corresponding decrease in the Froude number was found. However, for the bare plot and the S1 and S4 plots under a rainfall intensity of $120 \mathrm{~mm} / \mathrm{h}$, the raindrop kinetic energy to surface runoff was significantly increased and less kinetic energy was consumed with low vegetation coverage. Thus, this resulted in an increase in the flow turbulence intensity. Under the condition of vegetation coverage, the surface runoff was slowed not only by the friction effect of a rough plot surface but also by the vegetation drag force $[20,51]$. In this research, the increase in the resistance coefficient was caused by a combination of the slope surface, vegetation 


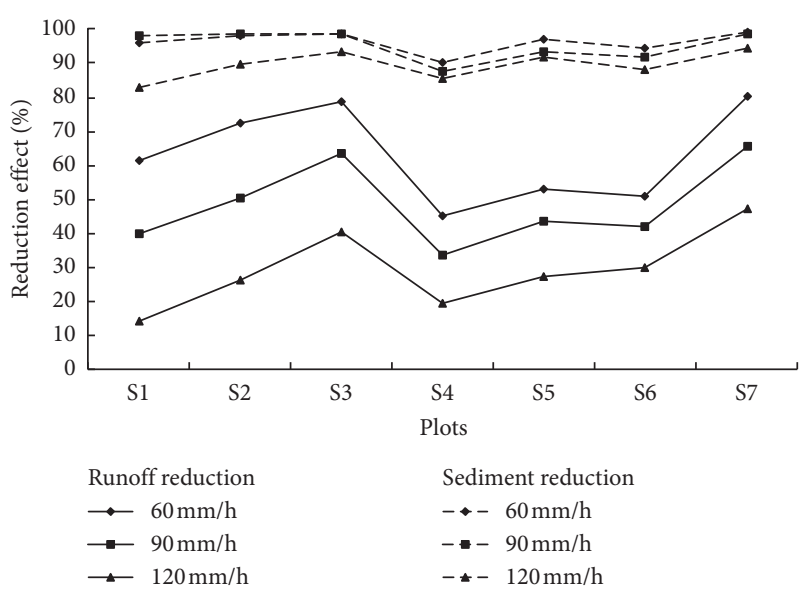

FIGURE 5: Runoff and sediment reduction effects under different vegetation covers and rainfall intensities.

type, and vegetation coverage. These results further explained why the herb-shrub mixed plot with high coverage had a better drag effect on surface runoff and thus reduced runoff and sediment loss.

4.4. Relationship between Runoff and Sediment. On the basis of an analysis of the laws of runoff generation and sediment yield, the change rule and relationship between the accumulated runoff volume and the accumulated sediment load were further analyzed, which was decided using experimental data through curve fitting. A power function relation, $Q_{\mathrm{s}}=A Q_{\mathrm{r}}^{B}\left(Q_{\mathrm{s}}\right.$ for the accumulative sediment load; $Q_{\mathrm{r}}$ for the accumulative runoff volume), exists between the accumulated runoff volume and the accumulated sediment load under various vegetation conditions and rainfall intensities (see Table 3). The determination coefficients of all the fitting equations were greater than 0.97 . These results indicated that there were good correlation coefficients between the accumulated runoff volume and the accumulated sediment load. The power function can describe the relationship between the accumulated sediment load and accumulated runoff volume in the soil erosion process. This result is consistent with analyses by Liang and $\mathrm{Yu}[28,44]$. The accumulated sediment load increases with increasing accumulated runoff volume during the rainfall process, though the increase in degree varies under different vegetation conditions and rainfall intensities.

By examining a comparative analysis of the power functions, it was found that there exists a certain law of the coefficients $A$ and $B$. According to the physical interpretation of runoff and sediment production and the mathematical concept, $A$ and $B$ are defined as the sediment yield cardinality coefficient and the sediment yield rate coefficient, respectively [44]. The value of $A$ depends on site conditions, and the higher the value of $A$ means the more amount of sediment yield. The value of $B$ depends on the soil infiltration rate, and the greater soil infiltration rate results in a smaller $B$ value $[44,52]$. The value of $B$ ranges from 0.82 to 2.37 , and most values are greater than 1 . This result is similar to the result of Li that found that the $B$ value of black soil in northeast China was greater than 1 [52]. Still, another study found that the $B$ value of the hillslope soil in the hilly and gully regions of the Loess Plateau ranged from 0.5 to 1 under different vegetation conditions [44]. The cause of these differences lies in the different site conditions and soil properties. Another reason is that prior to beginning the rainfall experiment in the research of $\mathrm{Li}$ et al. and this paper, a pilot rainfall $(30 \mathrm{~mm} / \mathrm{h})$ was applied to each experimental plot to allow the water to completely permeate through the soil and ensure the soil moisture remained the same for each rainfall event [52]. With a higher initial soil moisture, the soil reached adsorption saturation more easily and the accumulative runoff volume tended to be high [53], which resulted in a higher sediment yield rate coefficient $B$.

\subsection{Relationship between Vegetation Coverage, Rainfall In-} tensities, and Runoff Characteristics. The redundancy analysis (RDA) is a useful method for analyzing the relationship between species variables and environmental factors [32]. To analyze the response of runoff characteristics to vegetation coverage and rainfall intensity, a redundancy analysis was performed in this study (see Figure 6). The species variable matrix was formed with the runoff characteristics, and the environmental factor matrix was formed with the vegetation coverage and the rainfall intensity. In the RDA ordination diagram (see Figure 6), the arrowed line segment indicates the degree and size of the influence of environmental factors on species variables. The longer the line segment is, the smaller the angle between the line segments and the greater the influence [32]. Prior to the performance of RDA, a detrended correspondence analysis was performed to determine whether the linear model of RDA was appropriate for analyzing the data in this study [32]. The result indicates that the maximum length of the gradients of the four axes of runoff characteristics was 1.065 , suggesting that the linear RDA model was appropriate to analyze the relationship between runoff characteristics, rainfall intensity, and vegetation coverage. This was because the linear model was better than the unimodal model when the maximum gradient of the four axes was less than or equal to $3[32,37]$. Under the three different vegetation types (herbs, shrubs, and herbshrub mix), the percentages of variance of the runoff characteristics that were explained by the first axis and second axis were $93.1 \%, 98.3 \%$, and $94.7 \%$, respectively (see Table 4). This indicated that the relationship between the runoff characteristics, rainfall intensity, and vegetation coverage can be well explained by the first axis and second axis.

The RDA results mirrored the overriding effect of vegetation coverage and rainfall intensity in the runoff characteristics (see Figure 6). The three vegetation types (herb, shrub, and herb-shrub mix) had a similar direction of effect but varied in degree. As shown in Figure 6, for the three different vegetation types (herb, shrub, and herb-shrub mix), the Reynolds numbers and runoff volume were conspicuously associated with rainfall intensity. In addition, the Darcy-Weisbach friction coefficient and Manning's roughness coefficient were also significantly correlated with 
TABLE 3: Relationship between the accumulated runoff volume and the accumulated sediment load under different vegetation covers and rainfall intensities.

\begin{tabular}{|c|c|c|c|}
\hline Plots & $\begin{array}{l}\text { Rainfall } \\
\text { intensity } \\
(\mathrm{mm} / \mathrm{h})\end{array}$ & Regress equation & $\begin{array}{l}\text { Determination } \\
\text { coefficient } R^{2}\end{array}$ \\
\hline CK & $\begin{array}{c}60 \\
90 \\
120 \\
\end{array}$ & $\begin{array}{l}Q_{s}=0.9099 Q_{r}^{1.4249} \\
Q_{s}=6.0242 Q_{r}^{1.0792} \\
Q_{s}=22.885 Q_{r}^{0.9744}\end{array}$ & $\begin{array}{l}0.9998 \\
0.9993 \\
0.9983 \\
\end{array}$ \\
\hline S1 & $\begin{array}{c}60 \\
90 \\
120 \\
\end{array}$ & $\begin{aligned} Q_{s} & =0.2766 Q_{r}^{1.1847} \\
Q_{s} & =0.3249 Q_{r}^{0.9815} \\
Q_{s} & =1.9578 Q_{r}^{1.1494}\end{aligned}$ & $\begin{array}{l}0.9946 \\
0.9993 \\
0.9950 \\
\end{array}$ \\
\hline S2 & $\begin{array}{c}60 \\
90 \\
120\end{array}$ & $\begin{aligned} Q_{s} & =0.4155 Q_{r}^{0.9903} \\
Q_{s} & =0.1046 Q_{r}^{1.1679} \\
Q_{s} & =3.0267 Q_{r}^{0.9969}\end{aligned}$ & $\begin{array}{l}0.9917 \\
0.9842 \\
0.9991\end{array}$ \\
\hline S3 & $\begin{array}{c}60 \\
90 \\
120 \\
\end{array}$ & $\begin{array}{l}Q_{s}=0.2814 Q_{r}^{1.1162} \\
Q_{s}=0.1996 Q_{r}{ }^{1.0846} \\
Q_{s}=0.4393 Q_{r}^{1.3764}\end{array}$ & $\begin{array}{l}0.9977 \\
0.9989 \\
0.9970 \\
\end{array}$ \\
\hline S4 & $\begin{array}{c}60 \\
90 \\
120 \\
\end{array}$ & $\begin{aligned} Q_{s} & =1.5730 Q_{r}^{0.8379} \\
Q_{s} & =2.1957 Q_{r}^{0.9358} \\
Q_{s} & =5.4096 Q_{r}^{0.9125}\end{aligned}$ & $\begin{array}{l}0.9983 \\
0.9988 \\
0.9958 \\
\end{array}$ \\
\hline S5 & $\begin{array}{c}60 \\
90 \\
120 \\
\end{array}$ & $\begin{array}{l}Q_{s}=0.3672 Q_{r}^{0.9238} \\
Q_{s}=2.0375 Q_{r}^{0.8202} \\
Q_{s}=0.7500 Q_{r}^{1.2572}\end{array}$ & $\begin{array}{l}0.9964 \\
0.9984 \\
0.9997 \\
\end{array}$ \\
\hline S6 & $\begin{array}{c}60 \\
90 \\
120 \\
\end{array}$ & $\begin{array}{l}Q_{s}=0.3503 Q_{r}^{1.1694} \\
Q_{s}=0.4018 Q_{r}^{1.2604} \\
Q_{s}=3.3334 Q_{r}^{1.0211}\end{array}$ & $\begin{array}{l}0.9814 \\
0.9943 \\
0.9995\end{array}$ \\
\hline S7 & $\begin{array}{c}60 \\
90 \\
120\end{array}$ & $\begin{aligned} Q_{s} & =0.0097 Q_{r}^{2.3695} \\
Q_{s} & =0.4556 Q_{r}^{0.9495} \\
Q_{s} & =1.2953 Q_{r}^{1.1119}\end{aligned}$ & $\begin{array}{l}0.9702 \\
0.9993 \\
0.9979\end{array}$ \\
\hline
\end{tabular}

vegetation coverage. The responses of sediment rate and sediment load were strongly correlated with the rainfall intensity. The responses of runoff rate and the Froude number were similar and were to some extent correlated with the rainfall intensity. These results indicated that the rainfall intensity was the most important factor that influenced the Reynolds numbers and runoff volume and vegetation coverage was the most important factor that influenced the Darcy-Weisbach friction coefficient and Manning's roughness coefficient.

According to a comparison of the RDA of the three vegetation types, it was found that the resistance coefficients of herbs were the most sensitive to coverage changes. This result can further explain the reduction effect of vegetation type on runoff volume and sediment load. The herb can form a more intensive interception layer on a slope's surface with lower plant height; thus, herbs have a greater resistance coefficient and a better drag effect, which leads to a better runoff and sediment reduction effect. The Reynolds number and runoff volume of the herb-shrub mixed vegetation type showed the lowest relationship to rainfall intensity compared with other herb and shrub vegetation types. This result indicated that a change in the rainfall intensity had the least impact on the Reynolds number and runoff volume of the herb-shrub mix plot in this study. Therefore, the vegetation type of the herb-shrub mix had a better runoff reduction effect and a high control over the turbulent intensity of surface runoff in this study.

\section{Conclusions}

Vegetation cover and rock fragments content are parameters used that represent the effect of vegetation and rock fragment in most soil erosion research. This study focused on the soil containing rock fragment slopes in the Three Gorges reservoir to systematically explore the laws of runoff and sediment loads under different vegetation covers and rainfall intensities using artificial, simulated rainfall experiments. The results indicated that vegetation cover was an effective and acceptable method for reducing runoff and soil loss for soil containing rock fragments slope. The runoff volume decreased with increasing vegetation coverage and consequently decreased the sediment load under three different rainfall intensities. The vegetation cover reduced the runoff volume by $14.32 \%-80.51 \%$ and sediment load by $82.89 \%-$ $99.11 \%$ when compared with a bare plot. The runoff reduction and the sediment reduction increased with increasing vegetation coverage. Vegetation cover was more effective for sediment reduction. The vegetation-covered plot showed its best performance for soil erosion control when the herb-shrub mix coverage was applied. When Cynodon dactylon and Indigofera amblyantha were applied together, the soil loss was reduced by approximately $87.89 \%-99.11 \%$. An analysis of the runoff hydraulic characteristics showed that most of the plots had laminar and tranquil flow, while the CK plot and vegetation cover plot with a low coverage (60\%) under high rainfall intensity 


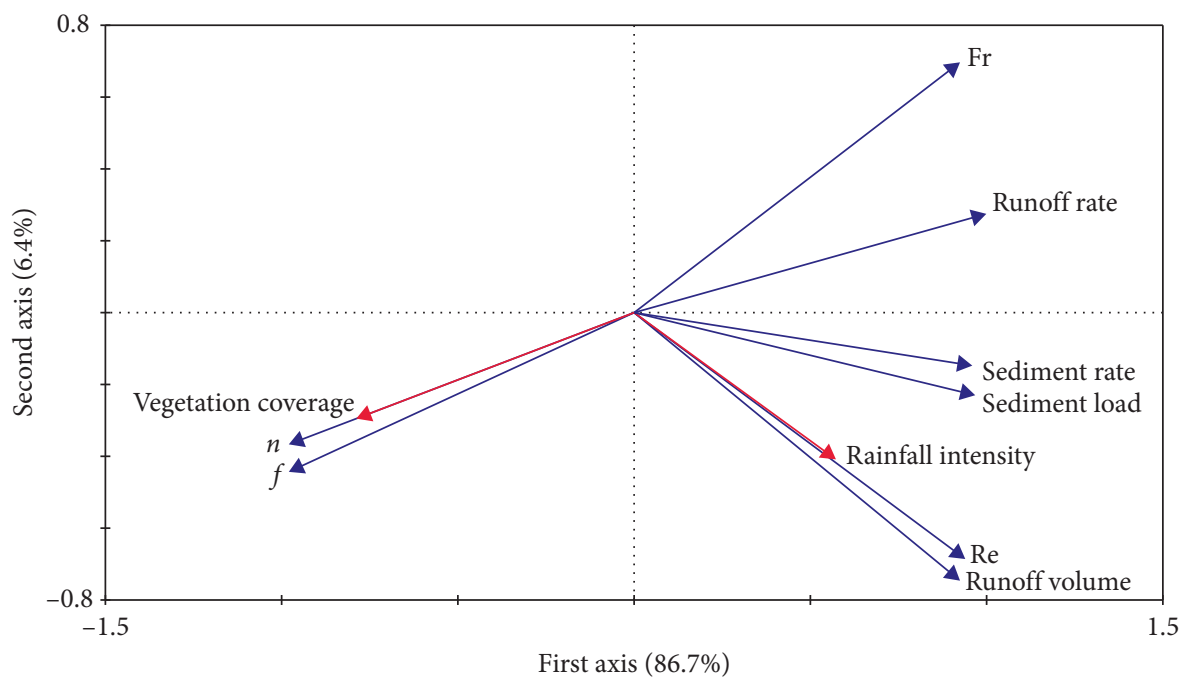

(a)

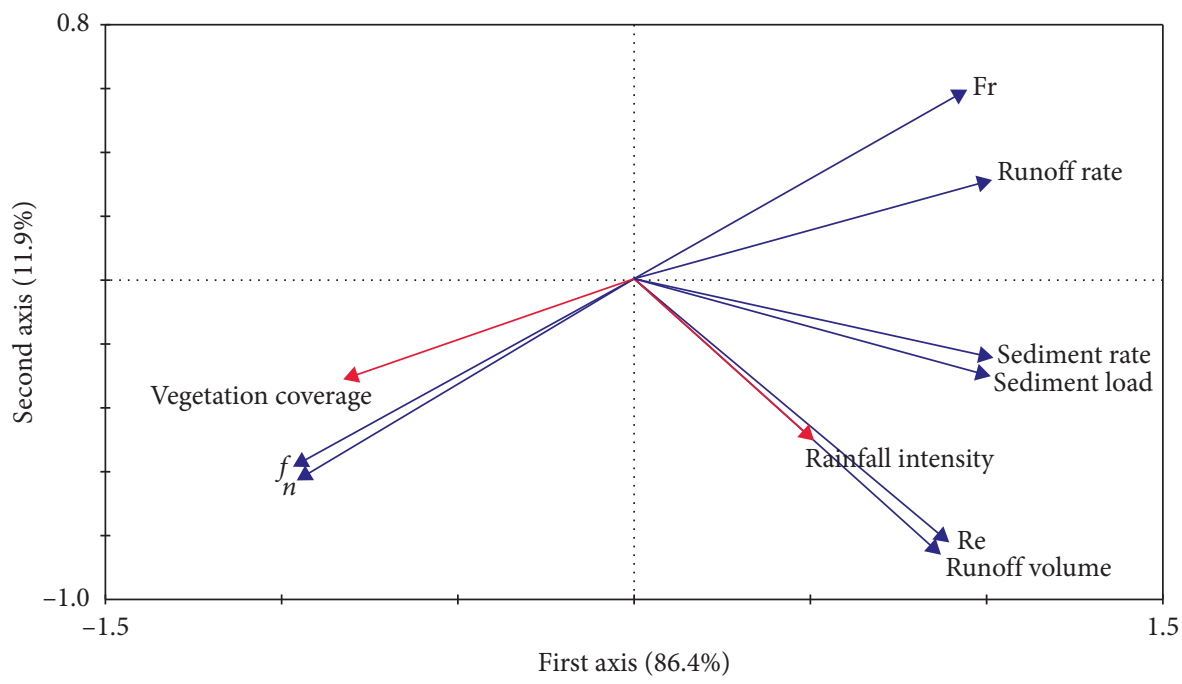

(b)

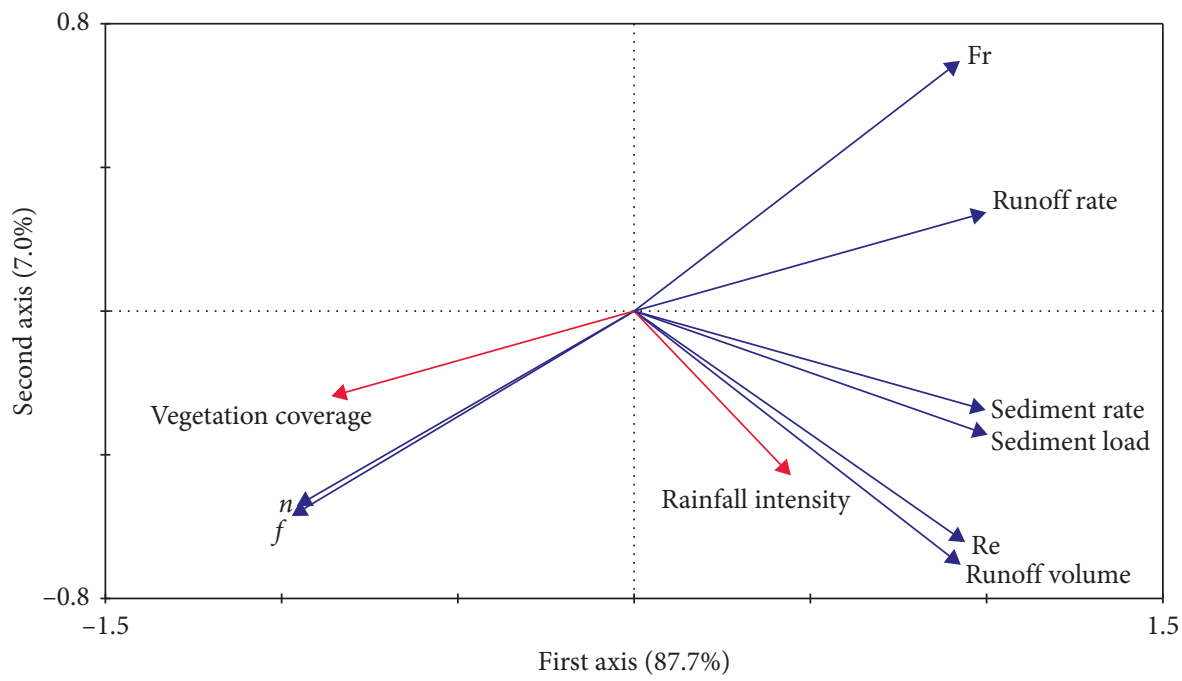

(c)

FIGURE 6: Ordination axes 1 and 2 of the RDA for runoff characteristics, vegetation coverage, and rainfall intensity. (a) Cynodon dactylon. (b) Indigofera amblyantha. (c) Cynodon dactylon and Indigofera amblyantha. 
TABle 4: Cumulative percentage variance, eigenvalue, and correlation coefficients for the first two axes of the RDA.

\begin{tabular}{lcc}
\hline Axis & AX1 & AX2 \\
\hline Cynodon dactylon & & \\
Eigenvalue & 0.867 & 0.064 \\
Correlation coefficients & 0.984 & 0.931 \\
Cumulative percentage variance (\%) & 86.7 & 93.1 \\
\hline Indigofera amblyantha & & \\
Eigenvalue & 0.864 & 0.119 \\
Correlation coefficients & 0.998 & 0.987 \\
Cumulative percentage variance (\%) & 86.4 & 98.3 \\
\hline Cynodon dactylon and Indigofera amblyantha & & \\
Eigenvalue & 0.877 & 0.070 \\
Correlation coefficients & 0.992 & 0.928 \\
Cumulative percentage variance (\%) & 87.8 & 94.7 \\
\hline
\end{tabular}

$(120 \mathrm{~mm} / \mathrm{h})$ were laminar and supercritical. In addition, the rainfall intensity was the most important factor that influenced the Reynolds numbers and runoff volume, and the vegetation coverage was the most important factor that influenced the Darcy-Weisbach friction coefficient and Manning's roughness coefficient. An increase in vegetation coverage can effectively increase the resistance coefficient, thus reducing runoff and sediment loss. A change in the rainfall intensity had the least impact on the Reynolds number and runoff volume of the herb-shrub mixed plot in this study. The Cynodon dactylon and Indigofera amblyantha mixed treatment had a better runoff reduction effect and a high control over the turbulence intensity of surface runoff in this study. Hence, it is suggested that the combination of Cynodon dactylon and Indigofera amblyantha and an increase in vegetation coverage be used to conserve soil and water loss to alleviate environmental stress on the Three Gorges reservoir and the Yangtze river. In addition, this study will promote the importance of soil conservation in the Three Gorges reservoir and increase researchers' understanding of the serious soil erosion issues in the region.

\section{Data Availability}

The data used to support the findings of this study are available from the corresponding author upon request.

\section{Conflicts of Interest}

The authors declare that there are no conflicts of interest regarding the publication of this paper.

\section{Acknowledgments}

This research was supported by the CRSRI Open Research Program (CKWV2019763/KY), the National Focal Research Program of China (2017YFC0504902-04), the Open Foundation of Engineering Research Center of Eco-Environment in Three Gorges Reservoir Region, the Ministry of Education, the China Three Gorges University (KF2016-04), the National Natural Science Foundation of China (51678348), and the Natural Science Foundation of Hubei Province (2016CFA085). We thank LetPub (http://www.letpub.com) for its linguistic assistance during the preparation of this manuscript.

\section{Supplementary Materials}

The supplementary material file is the raw data of our study. (Supplementary Materials)

\section{References}

[1] D. Pimentel, C. Harvey, P. Resosudarmo et al., "Environmental and economic costs of soil erosion and conservation benefits," Science, vol. 267, no. 5201, pp. 1117-1123, 1995.

[2] H. Hurni, K. Herweg, and B. Portner, Soil Erosion and Conservation in Global Agriculture, pp. 41-71, Springer, Dordrecht, Netherlands, 2008.

[3] Q. Cai, J. J. He, and L. Tian, "Coupling relationship between soil erosion control paradigm and ecology theory," Progress in Geography, vol. 26, pp. 11-20, 2007, in Chinese.

[4] H. Li, R. M. Cruse, R. L. Bingner, K. R. Gesch, and X. Zhang, "Evaluating ephemeral gully erosion impact on Zea mays L. yield and economics using AnnAGNPS," Soil and Tillage Research, vol. 155, pp. 157-165, 2016.

[5] C. Y. Liao, "The solution for practice and development of soil erosion prevention and control in the three gorges reservoir area, China," Soil and Water Conservation in China, vol. 1, pp. 1-3, 2009, in Chinese.

[6] P. Cui, Y. G. Ge, and Y. M. Lin, "Soil erosion and sediment control effects in the three gorges reservoir region, China," Journal of Resources and Ecology, vol. 2, no. 4, pp. 289-297, 2011.

[7] X. Xu, Y. Tan, G. Yang, H. Li, and W. Su, "Soil erosion in the three gorges reservoir area," Soil Research, vol. 49, no. 3, pp. 212-222, 2011.

[8] C. G. Wu, D. S. Lin, W. F. Xiao, P. C. Wang, H. Ma, and Z. X. Zhou, "Spatiotemporal distribution characteristics of rainfall erosivity in three gorges reservoir area," Chinese Journal of Applied Ecology, vol. 22, pp. 151-158, 2011, in Chinese.

[9] R. Huang, L. Huang, B. H. He, L. J. Zhou, and F. Wang, "Effects of slope forest and grass vegetation on reducing rainfall-runoff erosivity in three gorges reservoir region," Transactions of the Chinese Society of Agricultural Engineering, vol. 28, pp. 70-76, 2012, in Chinese.

[10] H. L. Zheng, J. Wei, G. J. Chen, and Y. B. Li, "Review of soil erosion on purple-soil sloping croplands in three gorges reservoir area," Journal of Chongqing Normal University, vol. 31, pp. 42-48, 2014, in Chinese.

[11] D. M. Shi, Y. S. Yang, X. X. Lu, and Y. Liang, "An analysis of soil erosion rules and sediment producing sources in the region of three-gorge of the Yangtze river," Journal of Soil \& Water Conservation, vol. 3, pp. 9-21, 1991, in Chinese.

[12] Q. H. Meng, L. Z. Yang, and L. Z. Yang, "Effects of land use on soil erosion and nutrient loss in the three gorges reservoir area, China," Soil Use and Management, vol. 17, no. 4, pp. 288-291, 2001.

[13] X. Y. Wang, T. W. Wang, C. F. Cai, and D. T. Xie, "Processes of rainfall infiltration, runoff and sediment yield on purple soil slope containing rock fragments," Advances in Water Science, vol. 25, pp. 189-195, 2014, in Chinese.

[14] D. Marc and H. Richard, "Reduction in agricultural non-point source pollution in the first year following establishment of an integrated grass/tree filter strip system in southern Quebec 
(Canada)," Agriculture Ecosystems \& Environment, vol. 131, pp. 85-97, 2009.

[15] Q. J. Wang, G. X. Zhao, Y. L. Liu, P. Y. Zhang, and J. Cai, "Effects of vegetation types on yield of surface runoff and sediment, loss of nitrogen and phosphorus along loess slope land," Transactions of the Chinese Society of Agricultural Engineering, vol. 14, pp. 195-201, 2016, in Chinese.

[16] H. T. Li, Y. J. Zhao, G. R. Li, X. S. Hu, H. J. Lu, and H. L. Zhu, "Experimental research on slope protection with vegetation under situ rainfall simulation in cold and arid environment of loess area," Research of Soil \& Water Conservation, vol. 6, pp. 304-311, 2014, in Chinese.

[17] Y. Gao, B. Zhu, P. Zhou, J.-L. Tang, T. Wang, and C.-Y. Miao, "Effects of vegetation cover on phosphorus loss from a hillslope cropland of purple soil under simulated rainfall: a case study in China," Nutrient Cycling in Agroecosystems, vol. 85, no. 3, pp. 263-273, 2009.

[18] D. A. Martens, "Relationship between plant phenolic acids released during soil mineralization and aggregate stabilization," Soil Science Society of America Journal, vol. 66, no. 6, pp. 1857-1867, 2002.

[19] M. A. Casermeiro, J. A. Molina, M. T. de la Cruz Caravaca, J. Hernando Costa, M. I. H. Massanet, and P. S. Moreno, "Influence of scrubs on runoff and sediment loss in soils of Mediterranean climate," Catena, vol. 57, no. 1, pp. 91-107, 2004.

[20] Q. L. Zhang, Z. L. Wang, D. D. Wang, and J. E. Liu, “Advances in researches of the effects of grassland vegetation on soil erosion in loess plateau," Advances in Earth Science, vol. 32, pp. 1093-1101, 2017, in Chinese.

[21] P. Q. Xiao, W. Y. Yao, Z. Z. Shen, and C. X. Yang, "Study on runoff and infiltration process and hydraulic parameters characteristics with grass coverage," Journal of Soil \& Water Conservation, vol. 23, pp. 50-53, 2009, in Chinese.

[22] L. L. Wang, W. Y. Yao, Z. Z. Shen, and C. X. Yang, "Effects of grass coverage on shallow flow hydraulic parameters and sediment reduction," Science of Soil \& Water Conservation, vol. 7, pp. 80-83, 2009, in Chinese.

[23] C. Z. Pan and Z. P. Shangguan, "Hydraulic characteristics of silt-laden flow on different gradient grassplots and its mechanism of sediment retention," Advances in Water Science, vol. 18, pp. 490-495, 2007, in Chinese.

[24] K. D. Zhang, G. Q. Wang, X. M. Sun, and J. J. Wang, "Hydraulic characteristic of overland flow under different vegetation coverage," Advances in Water Science, vol. 25, pp. 825-834, 2014, in Chinese.

[25] P. P. Yang, H. L. Zhang, Y. J. Wang, Y. Q. Wang, B. Wang, and Y. D. Liu, "Impact of spatial configuration mode of rigid vegetation on overland flow dynamics," Journal of Soil \& Water Conservation, vol. 29, pp. 90-95, 2015, in Chinese.

[26] P. Q. Xiao, W. Y. Yao, L. Li, and C. X. Yang, "Experimental study of overland flow resistance of different vegetation covers," Journal of Sediment Research, vol. 3, pp. 1-5, 2013, in Chinese.

[27] C. C. Meng, H. L. Zhang, and P. P. Yang, "Effects of simulated vegetation types and spatial patterns on hydrodynamics of overland flow," Journal of Soil \& Water Conservation, vol. 31, pp. 51-56, 2017, in Chinese.

[28] Y. Z. Liang, Z. Y. Xia, P. H. Niu, W. N. Xu, and Y. Chen, "Rainfall infiltration and characteristics of runoff and sediment yield in small watershed of three gorges reservoir area," Journal of Yangtze River Scientific Research Institute, vol. 33, pp. 28-32, 2016, in Chinese.
[29] F. Chen, Y. Xu, C. Wang, and J. Mao, "Effects of concrete content on seed germination and seedling establishment in vegetation concrete matrix in slope restoration," Ecological Engineering, vol. 58, pp. 99-104, 2013.

[30] U. K. Mandal, K. V. Rao, P. K. Mishra et al., "Soil infiltration, runoff and sediment yield from a shallow soil with varied stone cover and intensity of rain," European Journal of Soil Science, vol. 56, no. 4, pp. 435-443, 2005.

[31] C. Pan and Z. Shangguan, "Runoff hydraulic characteristics and sediment generation in sloped grassplots under simulated rainfall conditions," Journal of Hydrology, vol. 331, no. 1-2, pp. 178-185, 2006.

[32] Q. Zhao, D. Li, M. Zhuo, T. Guo, Y. Liao, and Z. Xie, "Effects of rainfall intensity and slope gradient on erosion characteristics of the red soil slope," Stochastic Environmental Research and Risk Assessment, vol. 29, no. 2, pp. 609-621, 2015.

[33] L. S. Wang, Q. G. Cai, C. F. Cai, and L. Y. Sun, "Study of hydrodynamic characteristics of rill and inter-rill flows on loess slopes," Journal of Sediment Research, vol. 8, no. 8, pp. 45-52, 2013, in Chinese.

[34] L. S. Wang, Q. G. Cai, C. F. Cai, and L. Y. Sun, "Hydrodynamic characteristics of stable growth-rill flow on loess slopes," Progress in Geography, vol. 33, pp. 1117-1124, 2014, in Chinese.

[35] S. F. Wu, Y. D. Zhang, and C. F. Bu, "Experimental study on rill erosion processes and flow hydraulic characteristics on loess gentle slope," Journal of Sediment Research, vol. 6, pp. 72-80, 2015, in Chinese.

[36] H. Xiao, G. Liu, P. Liu, F. Zheng, J. Zhang, and F. Hu, "Response of soil detachment rate to the hydraulic parameters of concentrated flow on steep loessial slopes on the loess plateau of China," Hydrological Processes, vol. 31, no. 14, pp. 2613-2621, 2017.

[37] Q. Zhao, S. Liu, L. Deng, S. Dong, and C. Wang, "Soil degradation associated with water-level fluctuations in the manwan reservoir, lancang river basin," Catena, vol. 113, pp. 226-235, 2014.

[38] J. LepŠ and P. Šmilauer, Multivariate Analysis of Ecological Data Using CANOCO, Cambridge University Press, Cambridge, UK, 2003.

[39] L. Wu, M. Peng, S. Qiao, and X.-Y. Ma, "Effects of rainfall intensity and slope gradient on runoff and sediment yield characteristics of bare loess soil," Environmental Science and Pollution Research, vol. 25, no. 4, pp. 3480-3487, 2018.

[40] F. Laio, A. Porporato, L. Ridolfi, and I. Rodriguez-Iturbe, "Plants in water-controlled ecosystems: active role in hydrologic processes and response to water stress: II. Probabilistic soil moisture dynamics," Advances in Water Resources, vol. 24, no. 7, pp. 707-723, 2001.

[41] D. Somchai and C. Chaiyuth, "Effects of rainfall intensity and slope gradient on the application of vetiver grass mulch in soil and water conservation," International Journal of Sediment Research, vol. 27, pp. 168-177, 2012.

[42] J. Lin, G. Zhu, J. Wei, F. Jiang, M.-K. Wang, and Y. Huang, "Mulching effects on erosion from steep slopes and sediment particle size distributions of gully colluvial deposits," Catena, vol. 160, pp. 57-67, 2018.

[43] X. Zhang, G. Q. Yu, Z. B. Li, and P. Li, "Experimental study on slope runoff, erosion and sediment under different vegetation types," Water Resources Management, vol. 28, no. 9, pp. 2415-2433, 2014.

[44] G. Q. Yu, Z. B. Li, P. Li, X. Zhang, L. Chen, and L. L. Jia, "Effects of vegetation types on hillslope runoff-erosion and 
sediment yield," Advances in Water Science, vol. 21, pp. 593-599, 2010.

[45] E. Sirjani and M. Mahmoodabadi, "Effects of sheet flow rate and slope gradient on sediment load," Arabian Journal of Geosciences, vol. 7, no. 1, pp. 203-210, 2014.

[46] L. Chen, Z. B. Li, P. Li, G. Q. Yu, and L. Jia, "The coupling effect on soil erosion and nutrient lost under a simulated rainfall," Journal of Basic Science \& Engineering, vol. 19, no. S1, pp. 170-176, 2011, in Chinese.

[47] T. Gong, Y. Zhu, and M. A. Shao, "Effect of embedded-rock fragments on slope soil erosion during rainfall events under simulated laboratory conditions," Journal of Hydrology, vol. 563 , pp. 811-817, 2018.

[48] Q. Ran, D. Su, P. Li, and Z. He, "Experimental study of the impact of rainfall characteristics on runoff generation and soil erosion," Journal of Hydrology, vol. 424-425, pp. 99-111, 2012.

[49] Z. Y. Zhang, Y. C. Wu, J. Yang, D. Xing, and L. Y. Wang, "Runoff generation and nutrient loss under different modes of cultivation in red-soil sloping land," Journal of Hohai University, vol. 41, pp. 241-246, 2013, in Chinese.

[50] H. Xiao, G. Liu, P. L. Liu, F. L. Zheng, J. Q. Zhang, and F. N. Hu, "Sediment transport capacity of concentrated flows on steep loessial slope with erodible beds," Scientific Reports, vol. 7, no. 1, p. 2350, 2017.

[51] F. Yang, K. D. Zhang, M. Y. Yang, and J. J. Wang, "Experimental study on hydraulic characteristics of flow under vegetation stem," Journal of Sediment Research, vol. 4, pp. 22-27, 2016, in Chinese.

[52] H. L. Li, X. Han, Z. D. Zhang, J. N. Li, H. C. Jiang, and X. L. Luo, "Research on runoff and erosion sediment under simulated rainfall conditions of black soil in northeast China," Journal of Soil \& Water Conservation, vol. 27, pp. 48-49, 2013, in Chinese.

[53] E. Daly and A. Porporato, "A review of soil moisture dynamics: from rainfall infiltration to ecosystem response," Environmental Engineering Science, vol. 22, no. 1, pp. 9-24, 2005. 


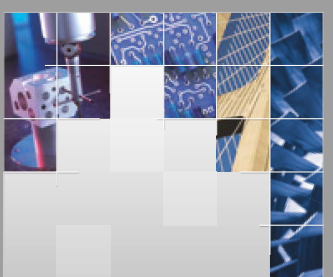

\section{Enfincering}
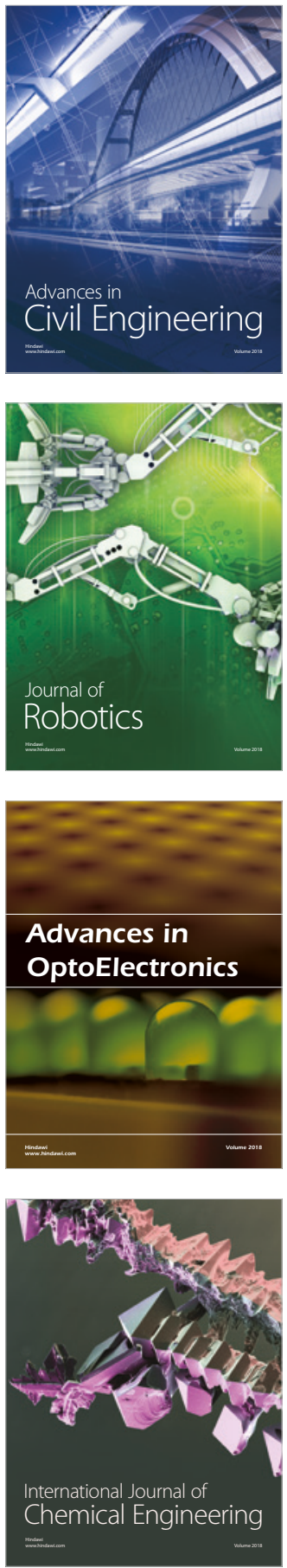

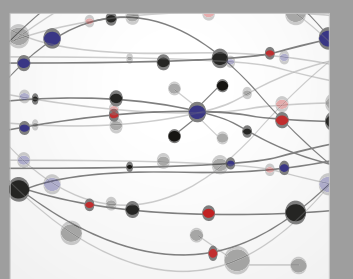

\section{Rotating \\ Machinery}

The Scientific World Journal

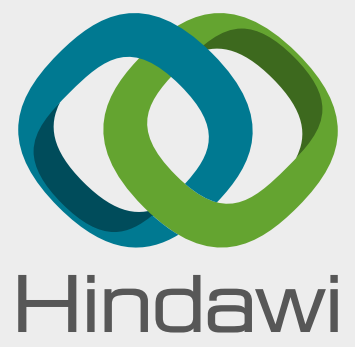

Submit your manuscripts at

www.hindawi.com
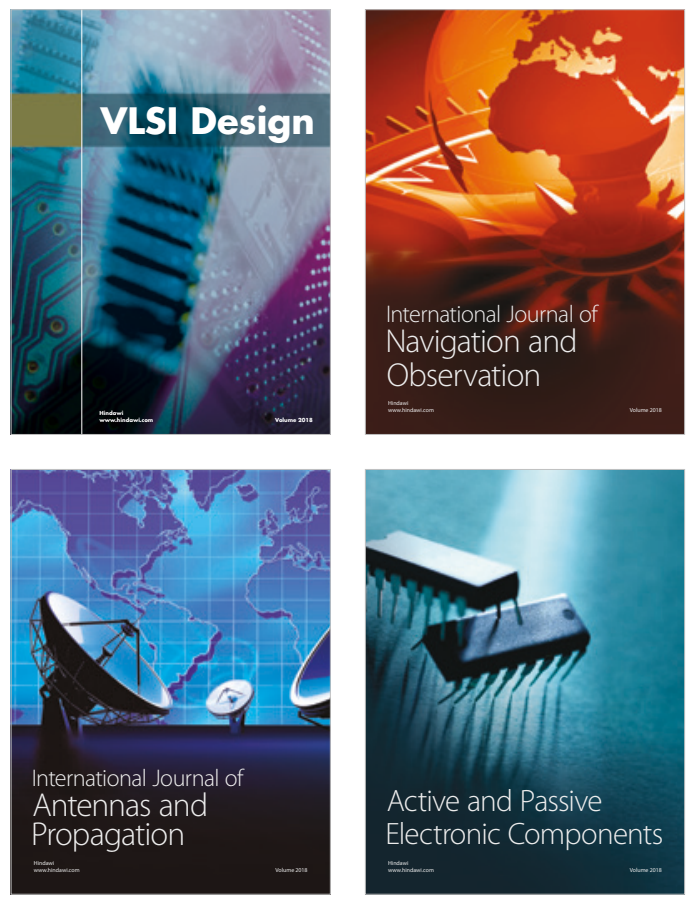
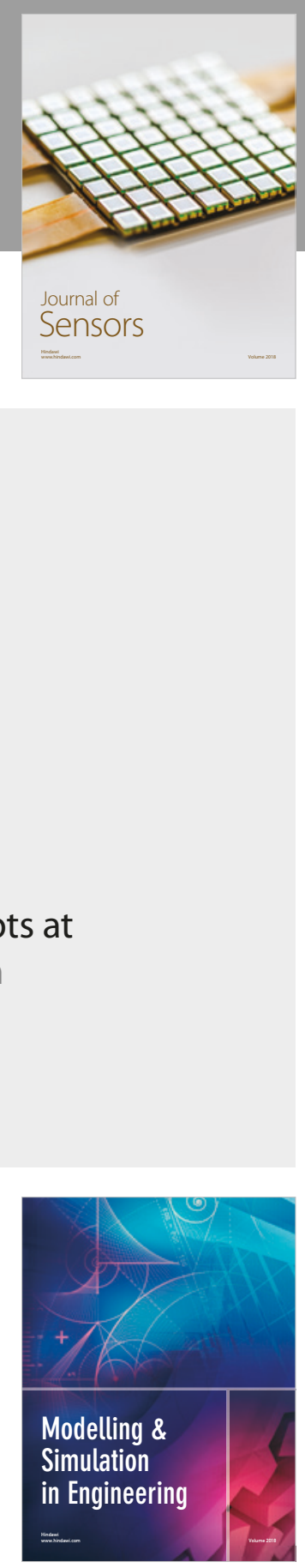

\section{Advances \\ Multimedia}
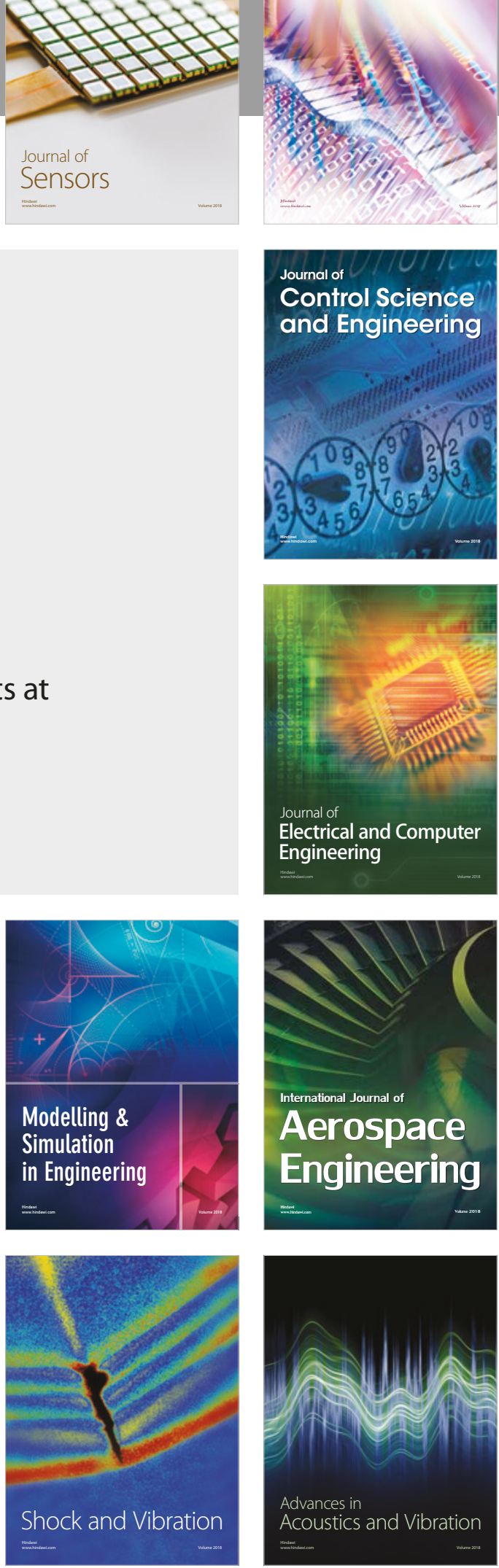